Başvuru : 07.02.2019

Kabul : 06.02.2020

\title{
Küçük ve Orta Ölçekli Otellerde Yönetsel Etkinliğin İş Doyumuna Etkisi: Batı Karadeniz Örneği ${ }^{1}$
}

\author{
Said Kıngır ${ }^{2}$ \\ Dilara Eylül Koç3 \\ Nilüfer Şahin Tezcan ${ }^{4}$ \\ Ömer Saraç 5
}

\section{Küçük ve Orta Ölçekli Otellerde Yönetsel Etkinliğin İş Do- yumuna Etkisi: Batı Karadeniz Örneği}

\section{Öz}

Örgütlerin amaçlarına ulaşabilmesinde iş doyumu yöneticiler için önem arz etmektedir. İş doyumu üzerinde etkisi bulunan birçok değişken vardır. Yöneticilerin sahip oldukları yönetsel etkinlik kavramı da bunlardan biridir. Nicel araştırma yöntemlerinin işe koşulduğu bu araştırmada küçük ve orta ölçekli otellerdeki yönetsel etkinliğin iş doyumu üzerindeki etkisinin ölçülmesi amaçlanmıştır. Bu doğrultuda veriler anket tekniği ile toplanmıştır. Araştırmanın uygulama alanı, Batı Karadeniz'de yer alan küçük ve orta ölçekli otellerdir. Bu otellerde çalışanlardan elde edilen 388 adet anket ile araştırmanın amaçları doğrultusunda frekans analizleri, $\mathrm{t}$ testi, ANOVA ve regresyon analizleri yapılmış, elde edilen sonuçlar yorumlanmıştır. Yapılan analizler sonucunda iş doyumunun, iş görenlerin gelir seviyesi, işletmedeki pozisyonları ve işletmedeki yönetsel etkinliğe yönelik bakış açılarına göre istatistiksel olarak anlamlı bir farklılığın olduğu ve yönetsel etkinliğin iş doyumu üzerinde etkisi olduğu sonuçlarına ulaşılmıştır.

Anahtar Kelimeler: Yönetsel Davranış, Yönetsel Etkinlik, Motivasyon, İş Doyumu, Otel İşletmeleri
The Impact of Managerial Effectiveness on Job Satisfaction at Small and Medium-Scale Hotels: The Example of Western Black Sea

\section{Abstract}

Job satisfaction is important for managers in achieving their goals. There are many variables that affect job satisfaction. The notion of managerial effectiveness that managers have, is one of them. In this study that quantitative research methods are used. It is aimed to measure the effect of managerial activity on job satisfaction in small and medium-sized hotels. Accordingly, the data were collected using a survey technique. The study implementation area is small and medium-scale hotels in Western Black. Frequency analyzes, $t$ test, ANOVA and regression analyzes were carried out with 388 questionnaires obtained from the employees and results were obtained and interpreted. As a result of the analyzes made, it has been found that there is a meaningful differences according to the viewpoints of job satisfaction, income levels, positions and managerial effectiveness in business, as well as the impact of managerial effectiveness has on job satisfaction of employees.

Keywords: Managerial Behavior, Managerial Effectiveness, Motivation, Job Satisfaction, Hotel Managements.

\section{Giriş}

Günümüze kadar gelen süreç içerisinde yaşanan gelişmeler toplum hayatlarında büyük değişikliklerin gerçekleşmesine neden olmuş, Sanayi Devriminden sonra hızla gelişen makineleşmeyle üretimde optimum fayda sağlamak için işgören yönetiminin değeri daha da artmıştır.

\footnotetext{
${ }^{1}$ Bu çalışmada; 20-21 Nisan 2018 tarihleri arasında Hatay'da tertip edilen 3. Uluslararası Doğu Akdeniz Turizm Sempozyumu'nda, sunulan bildiri, 3-5 Mayıs 2018 tarihleri arasında Antalya'da tertip edilen 4. Uluslararası Sosyal, Beşeri ve İdari Bilimler Sempozyumu'nda sunulan bildiri ve 5-7 Mayıs 2018 tarihleri arasında Antalya'da tertip edilen ASEAD 3. Uluslararası Sosyal Bilimler Sempozyumu'nda sunulan bildirilerden faydalanılmıştır.

2 Prof. Dr., Sakarya Uygulamalı Bilimler Üniversitesi Turizm Fakültesi, Turizm ve Otel İşletmeciliği Bölümü. saidkingir.sakarya.edu.tr, Yazar ORCID bilgisi: http://orcid.org/0000-0002-5459-3484

${ }^{3}$ Doktora Öğrencisi, Sakarya Uygulamalı Bilimler Üniversitesi Turizm İşletmeciliği Anabilim Dalı. dkoc@kastamonu.edu.tr, Yazar ORCID bilgisi: http://orcid.org/0000-0003-3990-7366 ${ }^{4}$ Doktora Öğrencisi, Sakarya Uygulamalı Bilimler Üniversitesi Turizm İşletmeciliği Anabilim Dalı. nilüfer-sahin-@hotmail.com,Yazar ORCID bilgisi: http://orcid.org/0000-0002-0403-5150

${ }^{5}$ Doktora Öğrencisi, Sakarya Uygulamalı Bilimler Üniversitesi Turizm İşletmeciliği Anabilim Dalı. o.sarach@hotmail.com, Yazar ORCID bilgisi: http://orcid.org/0000-0002-4338-7394
} 
İşgörenlerin zamanlarının en az üçte birini geçirdiği iş yerlerindeki iş doyumu ya da doyumsuzluğu, örgütün başarısının belirlenmesinde oldukça önemli bir yere sahiptir (Kara, 2010: 14). Bu nedenle, örgütlerde başarının yerini başarısızlığın aldığını gösteren en önemli unsur iş doyumunun düşük olmasıdır (Davis, 1988: 94). Zira yüksek iş doyumuna sahip işgörenler, görevlerini en iyi şekilde yerine getirmek için gereken çabayı göstermektedir (Tayfun ve Tekbalkan, 2014: 67).

Iş doyumunun çok önemli olduğu örgüt yapılarını bünyesinde barındıran sektörlerden biri de turizmdir. Turizm emek yoğun bir sektördür. İnsanın insana hizmet ettiği bu sektörde, örgütsel bağıılığın gerçekleşebilmesi için iş doyumu her geçen gün daha da önem kazanmaktadır. Bu doğrultuda örgütlerde etkinliğin sağlanabilmesinde, iş doyumunun arttırılması böylece örgütsel bağlılığın yüksek düzeye ulaşması hedeflenmektedir. Bu hedefe ulaşmada yönetsel etkinlik önemli bir rol oynamaktadır (Kelner, 1998).

Yönetsel etkinlikte, yöneticilerin örgütler üzerinde sergilemiş olduğu etkinlikten sonuç alabilmek için işgörenlerin güdülenmeleriyle ilgilenmeleri, yani işgörenlerde isteği yoğunlaştırmak, onları işe teşvik etmek ve örgütsel bir bağlılık oluşturmaları zorunlu bir hal almıştır. Bunu yaparken otantik bir liderliğin sergilenmesi saygılı ve hoşgörülü bir iş ortamın oluşmasını sağlayacak ve bunun getirdiği psikolojik rahatlık işgörenlerin iş doyumunu arttırarak yöneticiyi başarılı kılacaktır (Yener, 2018: 3). Çünkü yöneticinin başarısı, astlarının örgütsel amaçlar doğrultusunda bilgi, beceri ve yeteneklerini tam olarak kullanmasına bağlıdır (Başaran, 2004: 109). Yönetsel etkinliğin büyük ölçekli otellerde önemi olduğu kadar küçük ve orta ölçekli otellerde de önemli olduğu ve iş doyumuna fayda sağladığı düşünülmektedir. Özellikle küçük ve orta ölçekli otellerde yönetsel faaliyetlerin, büyük ölçekli otellere nispeten arka planda tutulması; işgörenlerin iş doyumunu olumsuz etkilemektedir. Küreselleşen dünyada varlığını sürdürmek isteyen oteller için iş doyumu hayati bir ehemmiyete sahiptir. Bu düşünceye koşut olarak yönetsel etkinliğin belirlenmesi ve iş doyumuna etkisinin ölçülmesinin önemi bu çalışmanın özgün değerini ortaya koymaktadır.

Bu çalışmada, Batı Karadeniz bölgesinde yer alan küçük ve orta ölçekli otellerin yönetsel etkinliğinin ve bu etkinliğin işgörenlerin, iş doyumlarına etkisinin ölçülmesi amaçlanmıştır. Araştırmada iş doyumu ölçeği çalışmaya uyarlanmış ve literatürden istifade ederek oluşturulmuş yönetsel etkinliğe ait ifadelerden yararlanılarak regresyon analizi yapılmıştır. Böylece yönetsel etkinliğin iş doyumunu açıklama oranı tespit edilmiştir.

Bu araştırmada küçük ve orta ölçekli otellerde yönetsel etkinliğin yetersiz olduğu ve işdoyumunu olumsuz etkilediği varsayılmıştır. Ancak araştırma yapılırken Batı Karadeniz'de yer alan tüm küçük ve orta ölçekteki otellere ve bu otellerde çalışan işgörenlere ulaşılamamıştır. Bunun nedeni, verilerin bir kısmının kış mevsiminde toplanmış olmasıdır. Bu mevsimde birçok otelin tadilat, temizlik ya da yenilenme nedenleriyle kapanması ve bununla birlikte durgun sezon gereği işgörenlerin bir kısmının işten ayrılması araştırmanın kısıtını oluşturmaktadır. Ayrıca, iş doyumunu etkileyen birçok neden olmasına karşın bu araştırmada sadece yönetsel etkinliğin belirlenmesi araştırmanın diğer sınırlılığıdır.

\section{Kavramsal Çerçeve}

İş doyumu en basit tanımıyla, işgörenlerin işlerinde sahip oldukları memnuniyet ya da memnuniyetsizlik olarak tanımlanmaktadır (Davis, 1988: 95; Gibson, Ivancevich ve Donnelly, 2000; Muchinsky, 2002). Başka bir deyişle iş doyumu, işgörenlerin kendilerine sağlanan ücret, işin kendisi, gözetim, çalışma grubu, çalışma koşulları, yönetim biçimi ve iş güvencesi gibi olanaklar sonucu ne kadar mutlu olduğunun bir göstergesidir (Baysal ve Tekarslan, 1996: 279; Vieira, 
2005: 39; Aşan ve Aydın, 2006: 88). Bu bağlamda işgörenlerin yüksek iş doyumuna sahip olması, işini sevmesi ve işine önem vermesiyle doğru orantılıdır (Akçadağ ve Özdemir, 2005: 172; Filiz 2014b: 794). Bunun için, istedikleri işi seçmelerinin yanı sıra, bu işin bilgi, beceri ve yeteneklerine sahip olmaları önem teşkil etmektedir. Bu durum onların işlerinde başarılı olmalarını sağlamakta ve maddi-manevi olarak ihtiyaçlarını karşılayabilmektedir. Bu ihtiyaçların karşılanmaması durumunda doyumsuzluk, bıkkınlık, kuralları önemsememe, savurganlık, işten şikâyet etme, örgüte zarar verme ve işten ayrılma eğilimleri görülmektedir (Başaran, 2000). Bu olumsuzlukların önüne geçmek ise şüphesiz etkin bir yönetimle mümkündür.

Yönetimin varlığı insanlık tarihi kadar eskidir. İnsanlar, belirli amaçlar doğrultusunda bir araya gelerek işbirliği halinde çalışmak için her daim yönetime ihtiyaç duymuşlardır. Bu bağlamda yönetim, kimi zaman bir süreç, kimi zaman yöneten ve yönetilen insanlar grubu ve kimi zaman da bilgi ve beceri topluluğu olarak işlev kazanmaktadır (Koçel, 1998: 10).

Yönetici ise örgütlerin amaçlarına ulaşabilmesinde yönetim işlevlerini yerine getiren ve en alt seviyeden en üst seviyeye kadar tüm faaliyetleri yöneten kişileridir. Yöneticiler, örgütteki etkinlik ve verimliliği sağlamak için eldeki tüm kaynakları optimum düzeyde kullanmayı amaçlamalıdır (Ülgen ve Mirze, 2013: 27). Bu düşünceye koşut olarak iş doyumunun sağlanmasında işletmelerin iyi bir yöneticiye sahip olması gerekmektedir. lyyi bir yöneticinin işgörenlerin ihtiyaç ve isteklerini belirlemesinde Maslow'un ihtiyaçlar hiyerarşisi büyük bir öneme sahiptir. Bu hiyerarşiye bakıldığında fizyolojik, güvenlik, ait olma, saygınlık ve kendini gerçekleştirme ihtiyaçları bir piramit şeklinde sıralanmış; Maslow, piramitte alt tabakada yer alan bir ihtiyacın karşılanmadan bir üstekine geçilemeyeceğini savunmuştur. Bu bağlamda işgörenlerin temel ihtiyaçlarının ücret ve iş güvencesi olduğu söylenebilmektedir. Bu sayede fiziksel ve güven ihtiyaçlarını karşılayacak olmaları iş doyumlarını da olumlu yönde etkileyecektir.

İ̧̧görenlerin aldığı maaş ile iş doyumları arasında çok güçlü bir ilişki vardır. Çünkü işgörenlerin çalışmasındaki temel amaç gelir elde etmektir. İ̧̧örenler ancak bu sayede fiziksel ihtiyaçlarını karşılayabilmektedir. Buna karşın ücret dağılımının adil olması, beklentilerinin karşılanması onları motive edebilmekte ve iş doyumlarını arttırabilmektedir (Telman ve Ünsal, 2004: 39-40). Bu durum işletmelerin de etkinliğinin artmasında önemli bir rol üstlenecektir.

İşgörenler açısından çalışma ortamı da iş doyumlarına etki eden bir diğer unsurdur. Bu ortamdaki ısı, nem, havalandırma, ışık, gürültü, güvenlik bakımından gerekli şartların yerine getirilmesi zaruridir. Çalışılan yerin işgörene yakın olması, temiz, iyi dekore edilmiş ve içerisindeki araç, gereç, alet ve edevatın kullanıma elverişli olması da iş doyumu açısından önem arz etmektedir (Khan, 1991: 8; Başaran, 2000: 204). Bu durum işgörenlerin çalışırken yaşayacakları bu tür zorluktan kurtulmalarını ve işlerine adapte olabilmelerini sağlayabilmeleri açısından iş doyumlarında olumlu bir etki oluşturacaktır.

İşgörenlerin örgütte çalışanlarla arasındaki ilişkinin yardımlaşma ve dayanışma üzerine kurulması, çalışanlar arasında ast ve üst ilişkilerin iyi olması iş doyumu açısından önem taşıyan diğer bir unsurdur (Horozoğlu, 1995:36; Başaran, 2004: 208). İ̧̧görenlere örgütsel faaliyetler içerisinde söz hakkı tanıyan yöneticiler, işgören tarafından benimsenmekte ve güvenilmektedir. Yöneticiler bu sayede işgörenlerin başarıya odaklı daha istekli olmasını sağlamaktadır. Yöneticilerin sahip oldukları tutum, takındıkları davranış ve işgörenlere verilen değer de önemlidir. Önemsendiklerini düşünen işgörenlerin işe olan enerjileri ve coşkuları artmakta; bu durum onların örgüte faydalı olmalarını sağlamaktadır (Aksayan, 1990: 21; Bingöl, 1995: 36-202; Akıncı, 2002: 8). 
Yöneticiler tarafından hedefe odaklı çalışmaya güdülenen işgörenlerin iş doyumları, göstermiş oldukları performans düzeyinde artmaktadır. Çünkü işgörenler yeteneklerini en üst seviyede kullanmak ve bilgilerinden azami ölçüde istifade etmek isterler. Böyle bir durumda yaptığı iş, işgörene başarma duygusunu tattırmakta böylece işletme amaçlarına ulaşmak için tüm bilgi ve yeteneklerini kullanmasını sağlamaktadır. Buna karşın ödül ve terfi işgörenlerin iş doyumlarında başka bir önemli unsurdur. Sarf ettikleri çaba karşısında bir ödülle mükâfatlandırılacağını ya da terfi alacağını düşünen işgörenler daha çok motive olmakta, güdülenmekte ve daha başarılı olmaktadır (İncir, 1990: 88; Erdoğan, 1997: 247; Eren, 2004: 515; Hechanova, Alampay ve Franco, 2006; Bağcı ve Mohan Bursalı, 2015). Böyle bir durumda toplumda kazanacakları saygınlık iş doyumlarına olumlu bir katkı sağlayacaktır.

Görüldüğü üzere, yönetsel etkinlik iş doyumunun kazanılmasında önem teşkil etmektedir. İ̧ doyumu ise, günümüze kadar geçen süreç içerisinde birçok araştırmaya konu olmuştur. Bu doğrultuda çalışmaların sayısının 5000 ile 7000 arasında değiştiği düşünülmektedir (Spector, 1997; Oshagbemi, 2000; Baş ve Ardıç, 2002:72). Bu çalışmaların birçoğunda işgören özellikleri ile iş doyumu arasında ilişki olduğu ortaya koyulmuş; bireysel ve örgütsel düzeydeki faktörler üzerinde durulmuştur (Futrell ve Parasuraman, 1984; Oshagbemi, 2000; Tarlan ve Tütüncü, 2000; Ilies ve Judge, 2002; Saari ve Judge, 2004; Lu vd., 2005; Kim, vd., 2005; Arı, 2015; Hinić, Grubor ve Brulić, 2017). İş doyumu ile alakalı yapılmış daha önceki bazı çalışmalara göre;

Herzberg vd., (1959) yapmış oldukları araştırmada insan davranışlarının, iş yerinde işgörenleri etkileyen olaylara ilişkin duyarlılık gösterdiğini ortaya koymuşlardır. Bu düşünceye koşut olarak olumlu etkiler iş doyumu sağlarken olumsuz etkiler iş doyumsuzluğuna neden olmaktadır. Herzberg vd, (1959) yapmış oldukları çalışmada ayrıca yaş ile iş doyumu arasında güçlü bir ilişkinin olduğunu ve bu ilişkinin " $U$ ” şeklinde bir eğri niteliğine sahip olduğunu bulgulamışlardır. Öte yandan araştırmada ücretin, iş doyumuna etkisi olmadığını buna karşın doyumsuzluğa engel olan faktörler arasında beşinci sırayı aldığını ortaya koymuşlardır. Loscocco (1990), cinsiyet ile iş doyumu arasındaki ilişkiyi ölçmeye yönelik yapmış olduğu araştırmada kadınların; görev çeşitliliğine, uğraştırıcı işlere ve iş yerlerine, erkeklere göre daha olumlu tepkiler verdikleri, maddi ödüllerle güdülenmelerinin yanı sıra, erkeklerde olduğu gibi işle alakalı istekleri olduğunu saptamıştır (Sun, 2002:40-41). Yaş ile iş doyumu arasındaki ilişkiyi ölçmeye yönelik araştırma yapan Ang vd., (1993) ise bu iki değişken arasında anlamlı bir ilişki olduğunu ortaya koymuşlardır. Yapılan çalışmada Herzberg vd., yapmış oldukları araştırmada koşutluk göstererek genç ve işe yeni başlayanlarda iş doyumu yüksek bir grafik çizerken, orta yaşlarda bu grafiğin düştüğünü; ancak ilerleyen yaşlarda yeniden yükseldiğini bulgulamışlardır. Bunun nedeninin; işe yeni başlayanlardaki heves, orta yaşlarda iş tecrübesinin yüksek düzeye ulaşması, ilerleyen yaşlarda ise, iş güvenliğinin oluşmasıyla alakalı olarak değişiklik gösterdiği düşünülmektedir. Voelck (1995)'in kütüphane çalışanları üzerine iş doyumuyla alakalı olarak yapmış olduğu araştırmada; çalışanların meslektaşlarından, kazançlarından ve denetimden memnun olmalarına karşın, kazandıkları ödül ve kendilerine sunulan fırsatlardan memnun kalmadıkları ve iş doyumları ile deneyimleri, eğitim durumları, mesai saatleri gibi değişkenler arasında istatistiksel olarak anlamlı farklılıklar olduğu sonuçlarına ulaşılmıştır. Taylor ve Tashakkori (1995)'in örgüt iklimi ve kararlara katılma ile iş doyumu arasında istatistiksel anlamlı bir ilişkinin olup olmadığını öğretmenler üzerinde yapmış olduğu uygulama ile incelendiği çalışmada, kararlara katılmanın iş doyumunu artırdığı sonucuna ulaşılmıştır. Winstead vd., (1995) çalışmalarında üniversite işgörenlerinin becerileri, iş arkadaşıkları ve iş doyumu ilişkisini incelemiş, iş arkadaşlıklarının iş doyumlarını po- 
zitif yönde etkiledikleri sonucuna ulaşmışlardır. Buna göre üniversitedeki işgörenler arkadaşlarıyla daha fazla birlikte olup iletişim kurma eğilimindedir. İ̧̧ arkadaşlarındaki değişiklik ise iş doyumunu olumsuz etkileyebilmektedir. Koustelios (2001) Yunanistan'da öğretmenler üzerine yapmış olduğu bir araştırmada öğretmenlerin almış oldukları ücretin iş doyumu üzerinde düşük düzeyde etkili olduğunu bulgulamıştır. Lam vd., (2001) Hong Kong'da Çin lokantalarındaki işgörenler üzerinde yaptıkları araştırma sonucunda, iş doyumu ile işgören devir hızı arasında anlamlı ilişki olduğunu ortaya koymuştur. Araştırmaya göre; iş doyumsuzluğu sonucu işten ayrılmalar artmıştır. Kuşluvan (2005)'in otel işgörenlerinin iş doyumunun ölçülmesi üzerine yapmış olduğu araştırmada iş doyumunun en çok insan kaynakları yönetimi uygulamaları ile alakalı olduğu ve işgörenlerin oteldeki sosyal ilişkilerden etkilendiği sonucuna ulaşıımıştır. Buna karşın stres ve rol faktörlerinin, işin özelliklerinin ve fiziksel ortamın iş doyumunu açıklamak açısından önemli olmadığı sonucuna ulaşmıştır. Uppal (2005) yapmış olduğu araştırmada her çalışanın adil şekilde ücret almak istediğini bulgulamıştır. Akçadağ ve Özdemir (2005) otel işgörenlerinin iş doyumunu ölçmeye yönelik yapmış olduğu çalışmada iş eğitimi, ek ücretler ve çalışma saatlerinin iyi düzenlenmiş olmasının iş doyumunu artırdığı sonuçlarına ulaşmıştır. Kıngır (2006) yaptığı çalışmada beş yıldızlı otellerin çeşitli yönetsel sorunlar yaşadığı, bu sorunları çözmek için gerekli yönetsel tekniklerin uygulanmadığı hatta bazı yöneticilerin bu soruların farkında bile olmadığı sonuçlarına ulaşmıştır. Chen (2007) yaptığı çalışmada, iş doyumunun; görevlerin tanımı, profesyonellik, geri bildirim, özerklik ve önemli olmak faktörleri olduğunu ortaya çıkmıştır. Kaya (2007)'nın otel işgörenlerinin iş doyumlarını ölçtüğü çalışmasında iş doyumunun eğitim seviyesine ve çalışılan departmana göre farklılık gösterdiği tespit edilmiştir. Toker (2007)'in otel işgörenlerinin iş doyumlarını ölçtüğü çalışmasında iş doyumunun yaş, medeni durum, eğitim seviyesi, turizm eğitimi ve çalışma sürelerine göre farklılık gösterdiği sonucuna ulaşılmıştır. Taşdan ve Tiryaki (2008) öğretmenlerin iş doyum düzeyi üzerine yapmış oldukları çalışmada iş ve işin niteliği, ücretler, çalışma şartları, işgören gelişme ve yükselme olanakları, takım arkadaşları ve örgütsel yaşam boyutlarıyla anlamlı farklılıklar tespit edilmiş, buna karşın cinsiyet, kıdem ve mezun olunan okul türüne göre anlamlı farklılıklar göstermediği bulgulanmıştır. Artık (2009) çalışmasında yöneticilerin karar alma, denetim ve yetki verme gibi personel güçlendirme uygulamalarının olması durumunda işgörenlerin iş doyumunun olumlu etkilendiğini tespit etmiştir. Ilıcak (2009) araştırmasında yöneticinin samimiyeti, astların gelişimine katkısı, disiplini sağlamadaki başarı ve yenilikçi eğilimlerinin iş doyumuna önemli derecede katkı sağladığı sonucuna ulaşmıştır. Ahsan vd., (2009) iş doyumu ve stresi arasındaki ilişkiyi tespit etmek üzere yapmış olduğu çalışmada iş doyumu ve iş stresi arasında güçlü negatif bir ilişkinin olduğu bulgulanmıştır. Tsai (2011) örgüt kültürleri, liderlik davranışı ve iş doyumu arasındaki ilişkiyi tespit etmek üzere yapmış olduğu çalışmada, özellikle liderlik davranışı ve iş doyumu arasında kuvvetli bir ilişki olduğu tespit edilmiştir. Yelboğa (2012) örgütsel adalet ile iş doyumu arasındaki ilişki tespit etmek amacıyla yapmış olduğu çalışmada örgütsel adaletin iş doyumunu belirleyen etmenlerden biri olduğu tespit edilmiştir. Braun vd., (2013) dönüşümcü liderlik, iş doyumu ve takım performansı arasındaki ilişkiyi tespit etmek üzere yapmış oldukları çalışmada dönüşümcü liderliğin hem bireysel hem de takım performansının artmasında iş doyumunun etkili olduğu sonucuna ulaşılmıştır. Filiz (2014) öğretmenlerin iş doyumu ve tükenmişlik düzeylerini tespit etmeye yönelik yapmış oldukları çalışmada iş doyumunun tükenmişlikle kuvvetli bir negatif ilişkisinin olduğu tespit edilmiştir. Çelik vd., (2015) otel işletmeleri üzerine yaptıkları bir araştırma sonucu etik liderliğin örgütsel bağ|ılık ve iş doyumu üzerinde, örgütsel bağlılığın iş doyumu üzerinde olumlu etkisi bulunduğu sonuçlarına ulaşmışlardır. Kaya ve Oğuzöncül (2016) iş doyumunu etkileyen 
faktörleri belirlemek üzere yapılan çalışmada geliri yüksek, işini isteyerek yapan ve işinin yeteneklerine uygun olan işgörenlerde iş doyumunun yüksek olduğu tespit edilmiştir. Büyükgöze ve Özdemir (2017) iş doyumu ile öğretmen performansı arasındaki ilişkilerin tespit edilmesi üzerine yapılan çalışmada erkek öğretmenlerin kadın öğretmenlere göre ve kıdemli öğretmenlerin nispeten kıdemsizlere göre iş doyumunun yüksek olduğu tespit edilmiştir. Ayrıca, iş doyumunun iş performansı üzerinde orta derecede etkili olduğu bulgulanmıştır.

Bu bilgilerin ışığında araştırmanın hipotezleri aşağıdaki gibidir:

H1: Yönetsel etkinlik iş doyumunu olumlu yönde etkilemektedir.

H2: Iş doyumu bazı bireysel özellikler bakımından farklılık göstermektedir.

\section{Araştırmanın Yöntemi}

\subsection{Araştırmanın Amacı}

Hizmet sektörü içinde önemli bir yeri olan turizm faaliyetlerinin gerçekleştirilmesinde küçük ve orta ölçekli işletmeler önem arz etmektedir. Bu işletmeler faaliyetlerini sürdürürken en büyük pay yöneticilere ve işgörenlere düşmektedir. Bu çalışma, yönetsel etkinliğin iş doyumu üzerinde bulunan etkisini ölçmek amacıyla gerçekleştirilmiştir. Araştırmaya konu olan iki değişken işletme faaliyetleri sürdürülürken çalışanlar ve yöneticiler üzerinde bazı doğrudan ve dolaylı etkilere sebep olabilmektedir. İşletme faaliyetlerinin en iyi şekilde yerine getirilmesi için iş doyumunu sağlamış işgörenlerin varlığı önemlidir. Bu konuda yöneticilerin yönetsel davranışları önem arz etmektedir. İşletme faaliyetleri üzerinde önemli etkilere sahip olan iş doyumu ve yönetsel etkinlik kavramlarının çalışma kapsamında ele alınması uygun görülmüştür.

\subsection{Veri Toplama Aracı}

Araştırmada nicel araştırma yöntemleri kullanılmıştır. Veri toplama aracı olarak anket tercih edilmiştir. Anket formlarının yapı olarak katılımcıya sunduğu seçenekler ile araştırmanın belirlenen çerçeve içinde gelişmesine imkân sağlaması anket formlarının kullanımını çekici kılmaktadır. Çalışma için kullanılan anket üç bölümden oluşmaktadır. Birinci bölümde, katılımcılara ait demografik ve bazı bireysel özelliklere yönelik 6 soruya yer verilmiştir. İkinci bölümde yönetsel etkinliğe ilişkin 8 ifade yer almaktadır. Sorular 2 seçenekli (evet-hayır) kapalı uçlu olacak şekilde hazırlanmıştır. Yönetim anlayışına özgü davranış biçimleri açıklanmaya çalışımıştır. Bu 8 ifade araştırma amacı doğrultusunda araştırılmak istenen konuya yönelik olacak şekilde, konuyla ilgili araştırma yapan çalışma yazarları tarafından uzman görüşleri alınarak oluşturulmuştur. Oluşturulan anket formu, araştırma yazarları tarafından örneklem olarak kabul edilen iller 3 farklı örneklem olacak şekilde ele alınarak analizlere tabi tutulmuş ve tutarlı veriler elde edilmiştir. Sonrasında çalışmaya veri toplamaya devam edilmiş ve yeterli sayıya ulaşıp analizler tekrar gerçekleştirilmiştir. Üçüncü bölümde ise iş doyumuna ilişkin 19 ifadeye yer verilmiştir. Artık (2009) tarafından geliştirilen geçerlilik ve güvenilirliği sağlanmış $5^{\prime} l i$ Likert tipi ölçek kullanılmıştır. Bu ölçekte yer alan soruların çalışmaya uygun yapıda olması, ölçekte herhangi bir değişiklik yapılmadan çalışmada tercih edilmesini sağlamıştır. Anketin üçüncü bölümündeki ifadeler için $5^{\prime} l i$ Likert Tipi ölçek tekniği kullanılmıştır. Anketin uygulandığı katılımcılardan her bir ifadeye (1) Kesinlikle Katılmıyorum, (2) Katılmıyorum, (3) Ne Katılıyorum Ne Katılmıyorum, (4) Katılıyorum, (5) Kesinlikle Katılıyorum seçeneklerinden birisini işaretleyerek değerlendirme yapmaları istenmiştir. 


\subsection{Araştırmanın Evreni ve Örneklemi}

Araştırma evrenini Batı Karadeniz Bölgesinde yer alan Bartın, Zonguldak, Kastamonu, Düzce, Karabük, Bolu ve Sinop illerinde bulunan küçük ve orta ölçekli tüm konaklama işletmesi çalışanları oluşturmaktadır. Ancak çalışanların tümüne ulaşmanın mümkün olmamasından dolayı örnekleme yoluna gidilmiştir. Örnekleme iştirak edecek katılımcıların belirlenebilmesi, hem anketin uygulanabilmesine olanak sağlanması, hem de çok miktarda veriye hızlı yoldan ulaşma gayesiyle olasılığa dayalı olmayan örnekleme türlerinden biri olan kolayda örnekleme yöntemi (Nakip, 2003) seçilmiştir. Bölgede bulunan küçük ve orta ölçekli işletmelerin sayısı ve bu işletmelerde sezon dışı istihdam edilen insan sayısı düşünülerek, toplamda 500 çalışana ulaşmak amacıyla yola çıkılıp 402 anket formuna geri dönüş olmuş ve anketlerden $388^{\prime}$ inin kullanılabilir olduğu tespit edilmiştir.

\subsection{Verilerin Analizi}

Elde edilen veriler analizlerin gerçekleştirilmesi için bilgisayar ortamına aktarılmış, SPSS programı ile çeşitli analizler yapılmıştır. Analiz olarak güvenilirlik analizi, frekans analizi, t testi, ANOVA testi ve regresyon analizinden yararlanılmıştır. Analizler sonucunda ortaya çıkan bulgular tablo haline getirilip raporlanmıştır.

Alfa katsayısına bakılarak ölçeğin güvenilirliği şöyle yorumlanmaktadır (Kalaycı, 2009: 405); $, 80 \leq \alpha<1,00$ aralığındaysa ölçeğin yapısı yüksek derece güvenilir, $60 \leq \alpha<, 80$ aralığındaysa ölçek yapısı oldukça güvenilir, $40 \leq \alpha<, 60$ aralığındaysa ölçeğin yapısı düşük derece güvenilir, $00 \leq \alpha$ $<0,40$ aralığındaysa ölçek güvenilir olmayan yapıdaki ölçektir.

Tablo 1: Iş̧ Doyum Ölçeği Iç̧in Güvenilirlik istatistiği Sonuçları

\begin{tabular}{ccc}
\hline Cronbach's Alpha Değeri & Standart Öğelere Göre Cronbach's Alpha Değeri & N \\
\hline \hline, 945 &, 945 & 19 \\
\hline
\end{tabular}

Sonrasında basıklık ve çarpıklık etkileri incelenerek verilerde dağılımın normallik gösterme durumunu anlamak amaçlanmıştır. Değerlerin olması gereken sınır değerler arasında bulunduğu kararına varılıp iş doyumuna ait olan ölçeğin normal dağılım koşuluna uygun olduğu (Kline, 2011) kabul edilerek, parametrik yapıda olan testleri uygulamaya karar verilmiştir.

\section{Bulgular}

Katılımcıların bireysel özelliklerine yönelik yüzde ve frekans bilgilerine tablo 2'de yer verilmiştir. Tabloya bakıldığında katılımcılardan \%52,1'i erkeklerden oluşurken \%47,9'ü kadınlardan oluşmaktadır. Medeni duruma bakıldığında \%39,2'i evliyken, \%60,8'si bekardır. Yaşa bakıldığında \%44,3'lük çoğunluğun 18-25 yaş aralığında olan bireylerden oluştuğu görülmektedir. Eğitim durumuna göre katılımcıların \%52,1'inin üniversite ve daha üzeri eğitim alan bireylerden oluştuğu görülmektedir. Katılımcıların \%33,8'i resepsiyonist olarak, \%18,8'i kat görevlisi olarak, $\% 29,6$ 'sı servis elemanı olarak, \%9'u mutfak çalışanı olarak ve \%8,8'i muhasebe işlerinde çalışmaktadır. Gelir düzeyi incelendiğinde $\% 87,4^{\prime} \mid$ ük çoğunluğun asgari ücret düzeyinde gelir elde ettiği görülmektedir. 
Eskişehir Osmangazi Üniversitesi ïBF Dergisi

Tablo 2: Araştırma Evrenine Yönelik Demografik ve Bazı Kişisel Bilgiler

\begin{tabular}{|c|c|c|c|c|c|}
\hline Cinsiyet & $\mathbf{N}$ & Yüzde (\%) & Medeni Durum & $\mathbf{N}$ & Yüzde (\%) \\
\hline Kadın & 186 & 47,9 & Evli & 152 & 39,2 \\
\hline Erkek & 202 & 52,1 & Bekar & 236 & 60,8 \\
\hline Yaş & & & Eğitim Düzeyi & & \\
\hline $18-25$ arası & 172 & 44,3 & Lise ve altı & 186 & 47,9 \\
\hline $26-30$ arası & 81 & 20,9 & Üniversite ve Üzeri & 202 & 52,1 \\
\hline $31-40$ arası & 90 & 23,2 & İşletmede Pozisyon & & \\
\hline 41 ve üzeri & 45 & 11,6 & Resepsiyon & 131 & 33,8 \\
\hline Gelir Seviyesi & & & Kat Hizmetleri & 73 & 18,8 \\
\hline Asgari Ücret & 339 & 87,4 & Servis Elemanı & 115 & 29,6 \\
\hline \multirow[t]{2}{*}{ Asgari ücret üzeri } & 49 & 12,6 & Mutfak & 35 & 9,0 \\
\hline & & & Muhasebe & 34 & 8,8 \\
\hline
\end{tabular}

Araştırmaya katılan bireylerin işletme içindeki yönetsel konulara yönelik bakış açılarının ölçülmesi amacıyla frekans ve yüzde analizleri gerçekleştirilmiştir. Çalışmaya katılanların yönetsel etkinlikle ilgili sorulara vermiş olduğu cevaplara yönelik frekans ve yüzde bilgilerine Tablo 3’de yer verilmiştir. Analiz sonuçlarına göre çalışmaya dahil olan işletme yöneticilerinin; çalışanlarının düşüncelerini önemsediği, onlara gelişim imkanları sağladığı, maaş ve sosyal güvenlik primlerinin ödemelerini düzenli ödediği, izin uygulamalarının düzenli olduğu sonuçlarına ulaşılmıştır. Fakat bu işletmelerde bireysel başarıların ödüllendirilmesi ve terfi olanaklarının sağlanması konusunda geri kalındığı sonuçlarına ulaşılmıştır. Bireysel ödül ve terfi konuları işletme personelinin doyumu üzerinde önemli etkilere sahip olan iki konudur. Bu konularda meydana gelebilecek ihtiyaçlar yöneticiler tarafından yakından izlenmeli ve karşılanmalıdır.

Tablo 3: Yönetsel Etkinlik Ifadelerine Yönelik Yüzde ve Frekans Değerleri

\begin{tabular}{|c|c|c|c|c|}
\hline \multirow[t]{2}{*}{ Yönetsel Etkinlikle İlgili ífadeler } & \multicolumn{2}{|c|}{ Evet } & \multicolumn{2}{|c|}{ Hayır } \\
\hline & Sıklık & (\%) & Sıklık & (\%) \\
\hline $\begin{array}{l}\text { 1.İşletmede yöneticiler çalışan düşüncelerine değer vermekte- } \\
\text { dir. }\end{array}$ & 298 & 76,8 & 90 & 23,2 \\
\hline 2.İşletmede çalışanlara kendini geliştirme imkânı sağlanır. & 309 & 79,6 & 79 & 20,4 \\
\hline 3.İşletme bireysel başarıları ödüllendirir. & 204 & 52,6 & 184 & 47,4 \\
\hline $\begin{array}{l}\text { 4.Personelin sosyal güvenlik primleri her ay eksiksiz şekilde ya- } \\
\text { tırılmaktadır. }\end{array}$ & 355 & 91,5 & 33 & 8,5 \\
\hline 5.Personelin ücretleri her ay eksiksiz olarak yatırılmaktadır. & 362 & 93,3 & 26 & 6,7 \\
\hline 6.İşletme çalışanlarına terfi imkânları sunmaktadır. & 203 & 52,3 & 185 & 47,7 \\
\hline $\begin{array}{l}\text { 7.Personelin çalışma koşulları her zaman daha iyi hale geti- } \\
\text { rilme eğilimindedir. }\end{array}$ & 284 & 73,2 & 104 & 26,8 \\
\hline 8. İşletmede haftalık izin uygulaması mevcuttur. & 356 & 91,8 & 32 & 8,2 \\
\hline
\end{tabular}

íki grup verileri arasındaki ortalamalarda anlamlı farklılık olup olmadığının tespiti için $t$ testleri gerçekleştirilmiştir. $t$ testleri ile çalışanların iş doyumunda cinsiyet, medeni durum, eğitim durumu ve gelir seviyesi bakımından ortaya çıkabilecek farklılıkların ölçülmesi amaçlanmıştır. Çalışmaya katılan kişilerin iş doyumunda cinsiyet, medeni durum ve eğitim durumundan kaynaklanan anlamlı farklılık meydana gelmezken; gelir seviyesi bakımından anlamlı farklılık ortaya çıktığı sonucuna ulaşıımıştır. Gelir seviyesinde meydana gelen bu farklıık; asgari ücret ve daha 
altı seviyede ücret alanların iş doyumu puanı 3,78 iken, asgari ücret üzeri ücret alanların iş doyumu puanı $4,15^{\prime}$ tir.

Çalışanın aldığı ücretin, iş doyumunda etkisi bulunan en etkin değişken olduğu söylenebilir. Yöneticiler çalışanlarının doyumunu üst seviyelerde tutmak amacıyla ücret düzenlemelerini en iyi şekilde yönetmelidir.

Tablo 4: Iş Doyumunda Gelir Seviyesi, Eğitim Durumu, Medeni Durum ve Cinsiyet Bakımından Meydana Gelen Farkların Incelenmesi

\begin{tabular}{|c|c|c|c|c|c|c|}
\hline & & \multicolumn{2}{|c|}{$\begin{array}{c}\text { Varyans Eşitliği İçin Le- } \\
\text { vene Test }\end{array}$} & \multirow[b]{2}{*}{$\mathbf{t}$} & \multirow[b]{2}{*}{ df } & \multirow[b]{2}{*}{ Sig (2-tailed) } \\
\hline & & $\mathbf{F}$ & Sig. & & & \\
\hline \multirow[t]{2}{*}{ Cinsiyet } & Eşit Sayılan Varyans & 1,861 & 0,173 & $-0,914$ & 386 & 0,361 \\
\hline & Eşit Sayılmayan Varyans & & & $-0,912$ & 377,553 & 0,363 \\
\hline \multirow{2}{*}{$\begin{array}{l}\text { Medeni } \\
\text { Durum }\end{array}$} & Eşit Sayılan Varyans & 0,000 & 0,984 & 0,192 & 386 & 0,848 \\
\hline & Eşit Sayılmayan Varyans & & & 0,194 & 330,374 & 0,847 \\
\hline \multirow{2}{*}{$\begin{array}{l}\text { Eğitim Du- } \\
\text { rumu }\end{array}$} & Eşit Sayılan Varyans & 8,018 & 0,005 & 0,675 & 386 & 0,500 \\
\hline & Eşit Sayılmayan Varyans & & & 0,671 & 364,040 & 0,503 \\
\hline \multirow{2}{*}{$\begin{array}{c}\text { Gelir } \\
\text { Seviyesi }\end{array}$} & Eşit Sayılan Varyans & 2,334 & 0,127 & $-3,385$ & 386 & 0,001 \\
\hline & Eşit Sayılmayan Varyans & & & $-4,116$ & 73,778 & 0,000 \\
\hline
\end{tabular}

Üç veya daha fazla grubun verileri arasındaki ortalamalarda anlamlı farklılık meydana gelip gelmediğinin testi amacı ile Anova testleri gerçekleştirilmiştir. Anova testleri ile çalışanların iş doyumunda yaş ve işletmedeki pozisyon bakımından ortaya çıkabilecek farklılıkların ölçülmesi amaçlanmıştır. Çalışmaya katılan kişilerin iş doyumunda yaş bakımından anlamlı farklıık meydana gelmezken; işletmedeki pozisyon bakımından anlamlı fark ortaya çıktığı tespit edilmiş olup bu farklılıklar tablo 5'de görülmektedir. Yapılan ikili karşılaştırmalar sonucu meydana gelen bu farkın muhasebe çalışanları ile kat hizmeti çalışanları arasında meydana geldiği tespit edilmiştir. Meydana gelen bu farklılık yapılan işin fiziksel zorluğundan kaynaklanıyor olabilir.

Tablo 5: İ̧ Doyumunda Yaş ile Pozisyona Göre Oluşan Farkların Incelenmesi

\begin{tabular}{ccccccc}
\hline & & Kareler Top. & df & Kareler Ort. & F & Sig. \\
\hline \hline Yaş & Gruplar Arası & 3,189 & 3 & 1,063 & 1,955 & 0,120 \\
& Grup Iç̧i & 208,747 & 384 & 0,544 & & \\
& Toplam & 211,936 & 387 & & & \\
\hline \hline \multirow{2}{*}{ Pozisyon } & Gruplar Arası & 11,767 & 4 & 2,942 & 5,629 & 0,000 \\
& Grup Iç̧i & 200,169 & 383 & 0,523 & & \\
& Toplam & 211,936 & 387 & & \\
\hline
\end{tabular}

İki grup (evet-hayır cevapları) verileri arasındaki ortalamalarda anlamlı fark oluşup oluşmadığının testi amacı ile t testleri gerçekleştirilmiştir. $t$ testleri yönetsel etkinlik ifadelerine göre iş doyumunda oluşabilecek farklılıkların ölçülmesi amacıyla yapılmıştır. Test sonuçlarına göre örnekleme dahil olan bireylerin yönetsel etkinlikle ilgili ifadelerden ilk 7 ifadeye göre anlamlı fark ortaya çıktığı sonucuna ulaşılmıştır. İş doyumu ile ilgili 1. ifadede (İ̧̧letmede yöneticiler çalışan düşüncelerine değer vermektedir.) ortaya çıkan farkı açıklamak gerekirse evet cevabını veren katılımcıların iş doyum ortalaması 4,01 çıkarken cevabı hayır olan katılımcıların ortalaması 3.20'dir. İş doyumu ile ilgili 2. ifadede (İşletmede çalışanlara kendini geliştirme imkânı sağlanır.) ortaya çıkan farkı açıklamak gerekirse evet cevabını veren katılımcıların iş doyum ortalaması 4,02 çıkarken cevabı hayır olan katılımcıların ortalaması 3.07'dir. İş doyumu ile ilgili 3. ifadede (İ̧̧letmede bireysel başarılar ödüllendirilir.) ortaya çıkan farkı açıklamak gerekirse evet cevabını 
veren katılımcıların iş doyum ortalaması 4,10 çıkarken cevabı hayır olan katılımcıların ortalaması 3.52'dir. İş doyumu ile ilgili 4. İfadede (İşletmede personel sosyal güvenlik primleri her ay eksiksiz yatırımaktadır.) ortaya çıkan farkı açıklamak gerekirse evet cevabını veren katılımcıların iş doyum ortalaması 3,91 çıkarken cevabı hayır olan katılımcıların ortalaması 2,88'dir. İş doyumu ile ilgili 5. ifadede (İşletmede personel ücretleri her ay eksiksiz şekilde yatırılmaktadır.) ortaya çıkan farkı açıklamak gerekirse evet cevabını veren katılımcıların iş doyum ortalaması 3,89 çıkarken cevabı hayır olan katılımcıların ortalaması 2,91'dir. İş doyumu ile ilgili 6. ifadede (işsletmede çalışanlara terfi imkânları sunulmaktadır.) ortaya çıkan farkı açıklamak gerekirse evet cevabını veren katılımcıların iş doyum ortalaması 4,03 çıkarken cevabı hayır olan katılımcıların ortalaması 3,59'dur. İş doyumu ile ilgili 7. İfadede (İşletmede personel çalışma şartları her zaman iyileştirilme eğilimindedir.) ortaya çıkan farkı açıklamak gerekirse evet cevabını veren katılımcıların iş doyum ortalaması 4,03 çıkarken cevabı hayır olan katılımcıların ortalamaları 3,26'dır.

Yönetsel etkinlikte sağlanan koşullara evet cevabı veren çalışanların iş doyumu puanlarının daha yüksek olduğu analiz sonuçlarından anlaşılmaktadır. Sağlanan imkânlar personelin iş doyumunu olumlu yönde etkilemektedir.

Tablo 6: Yönetsel Etkinlik ifadelerine Göre Iş Doyumunda Ortaya Çıkan Farkların Incelenmesi

\begin{tabular}{|c|c|c|c|c|c|c|}
\hline & & \multicolumn{2}{|c|}{$\begin{array}{l}\text { Varyans Eşitliği } \\
\text { Levene Test }\end{array}$} & \multirow[b]{2}{*}{$\mathbf{t}$} & \multirow[b]{2}{*}{ df } & \multirow[b]{2}{*}{ Sig (2-tailed) } \\
\hline & & $\mathbf{F}$ & Sig. & & & \\
\hline \multirow[t]{2}{*}{ Yönetsel-1 } & Eşit Sayılan Varyans & 17,092 & 0,000 & $-10,370$ & 386 & 0,000 \\
\hline & Eşit Sayılmayan Varyans & & & $-8,955$ & 121,415 & 0,000 \\
\hline \multirow[t]{2}{*}{ Yönetsel-2 } & Eşit Sayılan Varyans & 9,643 & 0,002 & $-11,823$ & 386 & 0,000 \\
\hline & Eşit Sayılmayan Varyans & & & $-10,075$ & 102,226 & 0,000 \\
\hline \multirow[t]{2}{*}{ Yönetsel-3 } & Eşit Sayılan Varyans & 5,170 & 0,024 & $-8,470$ & 386 & 0,000 \\
\hline & Eşit Sayılmayan Varyans & & & $-8,411$ & 365,541 & 0,000 \\
\hline \multirow[t]{2}{*}{ Yönetsel-4 } & Eşit Sayılan Varyans & 0,667 & 0,415 & $-8,354$ & 386 & 0,000 \\
\hline & Eşit Sayılmayan Varyans & & & $-7,147$ & 36,200 & 0,000 \\
\hline \multirow[t]{2}{*}{ Yönetsel-5 } & Eşit Sayılan Varyans & 0,740 & 0,390 & $-6,901$ & 386 & 0,000 \\
\hline & Eşit Sayılmayan Varyans & & & $-5,675$ & 27,333 & 0,000 \\
\hline \multirow[t]{2}{*}{ Yönetsel-6 } & Eşit Sayılan Varyans & 4,847 & 0,028 & $-6,124$ & 386 & 0,000 \\
\hline & Eşit Sayılmayan Varyans & & & $-6,092$ & 370,439 & 0,000 \\
\hline \multirow[t]{2}{*}{ Yönetsel-7 } & Eşit Sayılan Varyans & 18,445 & 0,000 & $-10,282$ & 386 & 0,000 \\
\hline & Eşit Sayılmayan Varyans & & & $-8,977$ & 146,549 & 0,000 \\
\hline
\end{tabular}

Regresyon analiziyle yönetsel etkinlik ile iş doyumu arasında oluşan etkinin yüzde değeri ortaya konulmaya çalışılmıştır. Sonuçlar tablo 7 ve 8 de görülmektedir.

Tablo 7: Regresyon Analizi Iç̧in Anova Testi Sonuçları

\begin{tabular}{|c|c|c|c|c|c|}
\hline Model & $\begin{array}{l}\text { Kareler } \\
\text { Toplamı }\end{array}$ & df & $\begin{array}{c}\text { Kareler } \\
\text { Ortalaması }\end{array}$ & $\mathbf{F}$ & Sig. \\
\hline Regresyon & 77,291 & 1 & 77,291 & 221,580 &, $000^{\mathrm{b}}$ \\
\hline Artan & 130,644 & 386 & 0,349 & & \\
\hline Toplam & 211,936 & 387 & & & \\
\hline
\end{tabular}

İş doyumu üzerinde yönetsel etkinliğin etkisini incelemek için oluşturulan modelde, $P<0,05$ çıkması modelin anlamlı olduğunu, yönetsel etkinlik değişkeninin iş doyumunu anlamlı şekilde açıkladığını göstermektedir. 
Tablo 8: Regresyon Analizi

\begin{tabular}{cccccc}
\hline $\mathbf{R}$ & $\mathbf{R}^{\mathbf{2}}$ & Ayarlanmış $\mathbf{R}^{\mathbf{2}}$ & $\begin{array}{c}\mathbf{R}^{\mathbf{2}} \\
\text { Değişim }\end{array}$ & F Değişim & $\begin{array}{c}\text { F Değişim } \\
\text { Anlamlılık }\end{array}$ \\
\hline \hline $0,604^{\text {a }}$ & $\mathbf{0 , 3 6 5}$ & 0,363 &, 365 & 221,580 & 0,000 \\
\hline
\end{tabular}

Yönetsel etkinliğin (bağımsız değişken), iş doyumunu (bağımlı değişken) açıklama düzeyinin incelenmesi için yapılan analiz sonucunda R2 değeri incelendiğinde 0,365 değeri ile \%36'lik bir etkinin olduğu görülmektedir. İş doyumunda oluşan \%36'lık değişim yönetsel etkinlikten kaynaklanmaktadır. Meydana gelen bu değişimin oranı göz ardı edilemeyecek boyuttadır. Otel işletmesi yöneticileri, çalışanlarının iş doyumunu üst seviyelere taşımak için, işletmelerini yönetirken sağladıkları koşullarda daha etkin olmak için çaba harcamalıdır.

\section{Sonuç}

Her işletme için olduğu gibi otel işletmelerinde de önem taşıyan konulardan biri iş doyumu konusudur. İ̧̧görenlerin iş doyumları ve yöneticilerin yönetsel etkinlikleri hakkında sonuç elde etmek amacı ile yapılan çalışma sonucunda iş doyumu konusunda gelir seviyesi ve işletmedeki pozisyona göre farklılıklar oluşabildiği sonucu elde edilmiştir. Çalışanların gelir durumları asgari ücret ve asgari ücretin altında olan seviyeden üst seviyeye yükseldikçe, iş konusunda elde edilen doyumda farklıık oluşmaktadır. Yapılan işler sonucu kazanılan gelir işten sağlanabilecek doyum ile ilişkili olan değişken durumundadır. İş doyumu işletme içinde sahip olunan pozisyon bakımından da farklılık göstermektedir. Meydana gelen bu farklılık belirgin şekilde kat hizmetleri çalışanları ile muhasebe çalışanları arasında gerçekleşmektedir. Bunun sebebi departmanlar arasında meydana gelebilen farklar (iş ortamı, iş yükü, iş tanımı vb. farklılıklar) olabilmektedir. Bu sorunun ortadan kaldırılabilmesi için İşletme yöneticilerine yük düşmektedir. Farklı bölümlerde çalışan kişilerin iş için maruz kaldığı koşullar mevcut imkanlar kullanılarak eşit düzeyde tutulmaya çalışılmalıdır. Her departmanın kendi içinde en iyi koşullara sahip olması sağlanabilir. Bu şekilde ortaya çıkabilecek farkların önüne geçilmesi sağlanır.

Iş doyumu ile yönetsel etkinlik arasındaki ilişkinin değerlendirilmesi için yapılan $t$ testleri sonucunda; çalışanlarının düşüncelerine değer veren, çalışanlara kendini geliştirmek için imkan tanıyan, çalışanların başarılarını ödüllendirmekte olan, sosyal güvenlik primlerini eksiksiz ödeyen, aylık ücretlerini eksiksiz yatıran, çalışanlara terfi imkanları sunan, çalışanların iş koşullarını her zaman daha iyi hale getirmeye çabalayan ve bu yöntemler sayesinde yönetsel etkinliklerini iyi seviyelerde tutmaya çabalayan işletmelerde çalışanların iş doyumu puanları tam tersi olan durumdaki işletmelere göre daha yüksek olduğu sonucuna ulaşılmıştır.

Çalışma sonucunda yönetsel etkinliğin iş doyumu üzerinde ortaya çıkan etkisi \%36 olduğu tespit edilmiştir. Bu sonuç çalışanların iş hakkındaki düşüncelerinde, işletmenin takip ettiği yönetim davranışları toplamının ne kadar etkili olduğunu göstermektedir. İşletmeler yönetim anlayışlarını sürekli daha iyi hale getirmek için çaba harcamalıdır. Yönetsel olarak etkin duruma gelen işletmeler, iş doyumu konusunda da etkin hale gelebilir. İşletme geleceği için iş doyumuna ulaşmış çalışanların varlığı şarttır. Bu çalışanlar, işlerinin gerekliliklerini kurumlarına bağlı şekilde yerine getirecektir.

Çalışmamızda elde edilen sonuçlar daha önce yapılmış olan bazı çalışmaların sonuçlarıyla uyumlu olsa da, (Taylor ve Tashakkori, 1995; Tsai, 2011; Voelck, 1995; Koustelios, 2001; Uppal, 2005; Taşdan ve Tiryaki, 2008; Artık, 2009; Ilıcak, 2009; Çelik vd., 2015, Kaya ve Oğuzöncül, 2016); bazı çalışmaların sonuçları ile uyuşmamaktadır (Herzberg vd., 1959; Ang vd., 1993; Voelck; 1995; Winstead, 1995; Lam vd., 2001; Akçadağ ve Özdemir, 2005; Kıngır, 2006; Chen, 
2007; Toker, 2007) meydana gelen bu farklılık; çalışmada kullanılan değişkenlerden, uygulama zamanından ya da uygulanan bölgeler arasındaki farklılıktan kaynaklanıyor olabilir.

İş doyumunun günümüz iş dünyası içinde büyük önem taşıyan konulardan biri olması göz ardı edilemeyecek gerçeklerdendir. Turizm sektörü hizmet sektörü içindeki yeri ve iş dünyasında sahip olduğu önem ile yapılan araştırmalara konu olmayı hak etmektedir. Yapılan bu çaIışmada turizm sektörünü başarıya ulaştırmak için en etkin faktör olan turizm sektörü çalışanlarının iş doyumunda etkisi bulunan çeşitli demografik değişkenlerin incelenmesi, yönetsel etkinliğin ele alınması ve iş doyumu ile yönetsel etkinlik ilişkisinin incelenmesi amacıyla temelde iki hipotez ortaya konmuştur. Bu hipotezler aşağıdaki gibidir;

H1: Yönetsel etkinlik iş doyumunu olumlu yönde etkilemektedir.

H2: İs doyumu bazı bireysel özellikler bakımından farklılık gösterebilir.

Yapılan araştırma sonucunda $\mathrm{H} 1$ hipotezi kabul olurken, $\mathrm{H} 2$ hipotezinin kısmı olarak kabul olduğu söylenebilir. Farklılığa neden olan değişkenlerin; gelir seviyesi ve işletmede sahip olunan pozisyon olduğu ortaya konmuştur.

Benzer konularda çalışmalar yapmak isteyecek araştırmacılar ve konaklama işletmesi yöneticileri için çeşitli öneriler ortaya koymak gerekirse iş doyumunun çalışma hayatı içindeki yerinin farkında olunmalı, öncelikle çalışanların memnuniyeti üzerinde durulmalıdır. Bu durum işletmeyi tercih eden müşterilerin tercihleri üzerinde de etkili olacaktır. Benzer konularda yapılacak olan çalışmalarda anket tekniğinin uygulanması için tercih edilecek olan zamanın turizm faaliyetlerinin yoğun olduğu sezonlarda olması daha büyük örneklem boyutlarına ulaşılmasını kolaylaştırabilir. Illerde yapılması düşünülen çalışmalar farklı bölgeleri ve daha fazla sayıda ili içerecek biçimde tasarlanabilir. 


\section{Kaynaklar}

Ahsan, Nilufar; Abdullah, Zaini; Fie, David, Yong, Gun; Alam, Syed, Shah (2009), “A Study of Job Stress on Job Satisfaction Among University Staff in Malaysia: Empirical Study", European Journal of Social Sciences, Vol. 8, No. 1, 121-131.

Akıncı, Zeki (2002), "Turizm Sektöründe İşgören İş Tatminini Etkileyen Faktörler: Beş Yıldızlı Konaklama İşletmelerinde Bir Uygulama”, Akdeniz Üniversitesi i.i.B.F.Dergisi, C. 2, S. 4, 1-25.

Akçadağ, Sibel; Özdemir, Ekrem (2005), “Insan Kaynakları Kapsamında 4 ve 5 Yıldızlı Otel İşletmelerinde İş Tatmini: İstanbul'da Yapılan Ampirik Bir Çalışma”, Kocaeli Üniversitesi Sosyal Bilimler Enstitüsü Dergisi, C. 10, S. 2, 167-193.

Aksayan, Seçil. (1990), Koruyucu ve Tedavi Edici Sağlık Hizmetlerinde Çalışan Hemşirelerin Iş̧ Doyumu Etkenlerinin Irdelenmesi, İstanbul Üniversitesi, Sağlık Bilimleri Enstitüsü, Yayınlanmamış Doktora Tezi. İstanbul.

Ang, Kong, Beng; Chye, Tee, Goh; Hian, Chye, Koh (1993), "The Impact of Age on the Job Satisfaciton of Accountants", Personnel Review, Vol. 22, No. 1, 31-39.

Arı, Erkan (2015). “Öğretmenlerin İş Doyumlarının Mesleki Tükenmişlik Üzerine Etkisinin Yapısal Eşitlik Modeli ile Araştırılması", Uluslararası Sosyal Araştırmalar Dergisi, C. 8, S. 39, 549-565.

Artık, Selçuk (2009), Yönetsel Davranış Biçimlerinin İ̧̧ Doyumuna Etkisi Üzerine Bir Araştırma, Atılım Üniversitesi, Sosyal Bilimler Enstitüsü, Yayınlanmamış Yüksek Lisans Tezi. Ankara.

Aşan, Öznur; Aydın, Eren Miski (2006), Örgütsel Davranış, (Ed. Halil Can), İstanbul: Arıkan Basım Yayım Dağıtım Ltd. Şti.

Bağcı, Zübeyir; Mohan Bursalı, Yeliz (2015), “Duygusal Emeğin İş Performansı Üzerindeki Etkisi: Denizli illinde Hizmet Sektöründe Görgül Bir Araştırma", Kafkas Üniversitesi iiBF Dergisi, C. 6, S. 10, 69-90.

Baş, Türker ve Kadir, Ardıç (2002), "Yüksek Öğretimde İş Tatmini ve Tatminsizliği”, iktisat İşletme ve Finans Dergisi, C. 17, S. 198, 72-81.

Başaran, İbrahim, Ethem (2004), Yönetimde Insan Illişkileri, 4. Baskı, Ankara: Nobel Yayınları.

Başaran, İbrahim Ethem (2000), Örgütsel Davranış-Insanın Üretim Gücü. Ankara: Feryal Matbaası.

Baysal, A., Can; Tekarslan, Erdal (1996), İşletmeciler Iç̧in Davranış Bilimleri, 2. Baskı, İstanbul: Nadir Kitap.

Bingöl, Dursun (1995), Personel Yönetimi, İstanbul: Beta Yayınları.

Braun, Susanne; Peus, Claudia; Weisweiler, Silke; Frey, Dieter (2013), “Transformational Leadership, Job Satisfaction, and Team Performance: A multilevel mediation model of trust", The Leadership Quarterly, Vol. 24, No. 1, 270-283.

Büyükgöze, Hilal; Özdemir, Murat (2017), “iş Doyumu ile Öğretmen Performansı İlişkisinin Duygusal Olaylar Kuramı Çerçevesinde İncelenmesi", Inönü Üniversitesi Eğitim Fakültesi Dergisi, C. 18, S. 1, 311-325.

DOI: 10.17679/inuefd.307041.

Chen, Ling, Hsiu (2007), "Job Satisfaction Among Information System (IS) Personnel”, Computers in Human Behavior, Vol. 24, No. 1, 105-118.

Çelik , Sedat; Dedeoğlu, Bekir, Bora \& İnanır , Ali (2015), "Relationship Between Ethical Leadership, Organizational Commitment and Job Satisfaction at Hotel Organizations", Ege Akademik Bakıss, C. 15, S.1, 53-63.

Davis, Keith (1988), İşletmelerde Insan Davranışı, (Çev. Kemal Tosun), İstanbul: İşletme Fakültesi Yayını.

Erdoğan, İlhan (1997), Işsletmelerde Davranış, İstanbul: İstanbul Üniversitesi İşletme Fakültesi Yayın.

Eren, Erol (2004), Örgütsel Davranış ve Yönetim Psikolojisi, İstanbul: Beta Basım.

Filiz, Zeynep (2014a), “Öğretmenlerin İ̧̧ Doyumu ve Tükenmişlik Düzeylerinin İncelenmesi”, Uluslararası Yönetim Iktisat ve işletme Dergisi, C. 10, S. 23, 157-172.

Filiz, Zeynep (2014b), "An Analysis of the Levels of Job Satisfaction and Life Satisfaction of the Academic Staff" Social Indicator Research, Vol. 116, No. 3, 793-808.

Futrell, Charles, M; A. Parasuraman (1984), "The Relationship of Satisfaction and Performance to Salesforce Turnover", Journal of Marketing, Vol. 48, No. 4, 33-40.

Gibson, James, L.; Ivancevich, John, M.; Donnelly, James, H. (2000), Organizations - Behavior - Structure - Processes, 10th Ed., Boston: McGraw-Hill.

Hechanova, Regina, M.; Alampay, Ramon, Benedicto. A.; Franco, Edna, P. (2006), "Psychological Empowerment, Job Satisfaction and Performance among Filipino Service Workers", Asian Journal of Social Psychology, Vol. 9, No. 1, 72-78.

Herzberg, Frederic; Bernard, Mausner; Barbara, B., Snyderman (1959), The Motivation to Work, Transaction Publishers (Originally Published in 1959 by John Wiley \& Sons, Inc.), New Jersey. 


\section{Eskişehir Osmangazi Üniversitesi IïB Dergisi}

Hinić, Darko; Grubor, Jelena; Brulić, Lida (2017), “Followership Styles and Job Satisfaction in Secondary School Teachers in Serbia", Educational Management Administration and Leadership, Vol. 45, No. 3, 503-520. doi: 10. 177/1741143215623787.

Horozoğlu, Şenol (1995), Çalışanların iş Doyum Düzeylerinin Karşılaştırılması, Hacettepe Üniversitesi, Sosyal Bilimler Enstitüsü, Yayınlanmamış Yüksek Lisans Tezi, Ankara.

Ilıcak, Emin (2009), Liderlerin Yönetsel Davranışları ile Çalışanların İş Tatmini Arasındaki ilişki, İnönü Üniversitesi, Sosyal Bilimler Enstitüsü, Yayınlanmamış Yüksek Lisans Tezi, Malatya.

Ilies, Remus; Timothy, A., Judge (2002), “Understanding the Dynamic Relationships among Personality, Mood and Job Satisfaction: A Field Experience Sampling Study", Organizational Behavior and Human Decision Processes, Vol. 89, No. 2, 1119-1139.

İncir, Gülten (1990), Çalışanların iş Doyumu Üzerine Bir Inceleme, Ankara: MPM Yayınları.

Kalaycı, Şeref (2009), SPSS Uygulamalı Çok Değişkenli İstatistik Teknikleri, Ankara: Asil Yayınları.

Kara, Merve, Miray (2010), The Relation of Job Satisfaction with Happiness and Success Level. Yüksek Lisans Tezi. Marmara Üniversitesi, Sosyal Bilimler Enstitüsü, Yayınlanmamış Yüksek Lisans Tezi, İstanbul.

Kaya, Ferit; Oğuzöncül, Ayşe, Ferdane (2016), “Birinci Basamak Sağlık Çalışanlarında İş Doyumu ve Etkileyen Faktörler", Dicle Medical Journal/Dicle Tip Dergisi, C. 43, S. 2, 248-255.

Kaya, İlke (2007), "Otel İşletmelerinde İşgörenlerin İş Tatminini Etkileyen Faktörler: Geliştirilen Bir İş Tatmini Ölçeği", Anadolu Üniversitesi Sosyal Bilimler Dergisi, C. 7, S. 2, 355-372.

Kelner, Steve (1998), "Managing the Climate of a TQM Organization", Center for Quality of Management Journal, Vol. 7, No. 1, 31-37.

Khan, Ali, Umar (1991), Satisfaction of Secondary School Administrators with Their Work in Pakistan, Orta Doğu Teknik Üniversitesi, Sosyal Bilimler Enstitüsü, Yayınlanmamış Doktora Tezi. Ankara.

Kıngır, Said (2006), “Bir Hizmet İ̧̧letmesi Olarak Beş Yıldızlı Otel İşletmelerindeki Yönetsel Sorunlar”, Selçuk Üniversitesi Sosyal Bilimler Enstitüsü Dergisi, S. 15, 457-481.

Kim, Woo, Gon; Jerrold, K. Leong; Yong-Ki, Lee (2005), "Effect of Service Orientation on Job Satisfaction, Organizational Commitment, and Intention of Leaving in a Casual Dining Chain Restaurant", International Hospitality Management, Vol. 24, No. 2, 171-193.

Kline, Rex (2011), Principles and Practice of Structural Equation Modeling, 3. Baskı, New York: The Guilford Press.

Koçel, Tamer (1998), işletme Yöneticiliği, 6. Baskı, İstanbul: Beta Yayınları.

Koustelios, D., Athanasios (2001), "Personal Characteristics and Job Satisfaction of Greek Teachers", The International Journal of Educational Management, Vol. 15, No. 7, 354-358.

Kuşluvan, Zeynep; Kuşluvan, Salih (2005), "Otel İşletmelerinde İş ve İşletme ile İlgili Faktörlerin İşgören Tatmini Üzerindeki Görece Etkisi: Nevşehir Örneği”, Anatolia: Turizm Araştırmaları Dergisi, C. 16, S. 2, 183-203.

Lam, Terry; Tom, Baum; Ray, Pine (2001), "Study of Managerial Job Satisfaction in Hong Kong's Chinese Restaurants", International Journal of Contemporary Hospitality Management, Vol. 13, No. 1: 35-42.

Loscocco, Karyn A. (1990), "Reactions to Blue-Collar Work: A Comaparison of Women and Men", Work and Occupations, Vol. 17, No. 2, 152-177.

Lu, Hong; E. While Alison; K. Louise, Barriball (2005), “Job Satisfaction Among Nurses: A Literature Review”, International Journal of Nursing Studies, Vol. 42, No. 2, 211-227.

Muchinsky, Paul, M. (2002), Psychology Applied To Work, 6th Ed., Belmont: Wadsworth Publishing Company.

Nakip, Mahir (2003), Pazarlama Araştırmaları Teknikler ve (SPSS destekli) Uygulamalar, Ankara: Seçkin Yayıncılık.

Oshagbemi, Titus (2000), "Is Length of Service Related to the Level of Job Satisfaction?", International Journal of Social Economics, Vol. 27, No. 3, 213-226.

Oshagbemi, Titus (2000), "Satisfaction with Co-Workers Behaviour", Employee Relation, Vol.22, No. 1, 88-106.

Saari, Lise, M.; Timothy A. Judge (2004), "Employee Attitudes and Job Satisfaction", Human Resource Management, Vol. 43, No. 4, 395-407.

Spector, Paul, E. (1997), Job Satisfaction: Application, Assessment, Causes and Consequences, London Sage Publications. 
Sun, H., Özlem (2002), İs Doyumu Üzerine Bir Araştırma: TCMB, Banknot Matbaası Genel Müdürlüğü, Yayınlanmamış Uzmanlık Tezi, TCMB, Banknot Matbaası Genel Müdürlüğü. Ankara.

Tarlan, Deniz; Tütüncü, Özkan (2001), "Konaklama İşletmelerinde Başarı Değerlemesi ve İş Doyumu Analizi”, Dokuz Eylül Üniversitesi Sosyal Bilimler Enstitüsü Dergisi, C. 3, S. 2, 141-163.

Taşdan, Murat; Tiryaki, Eda (2010), "Özel ve Devlet Illköğretim Okulu Öğretmenlerinin İş Doyumu Düzeylerinin Karşılaştırılması", Eğitim ve Bilim, C. 33, S. 147, 54-70.

Tayfun, Ahmet; Tekbalkan, Murat (2014). “Dış Kaynaklardan Yararlanan Otel İşletmelerinde Örgütsel Bağlılık ve İş Doyumu: Ankara'da Bir Araştırma", Gazi Üniversitesi Turizm Fakültesi Dergisi, (1), 63-78.

Taylor, Dianne; Tashakkori, Abbas (1995), "Decision Participation and School Climate as Predictors of Job Satisfaction and Teachers' Sense of Efficacy", Journal of Experimental Education, Vol. 63, No. 3, 217-230.

Telman, Nursel; Ünsal, Pınar (2004), Çalışan Memnuniyeti, İstanbul: Epsilon Yayınları.

Toker, Boran (2007), "Konaklama İşletmelerinde İş Doyumu: Demografik Değişkenlerin İş Doyumu Faktörlerine Etkisi Üzerine Bir Çalışma", Journal of Yasar University, C. 2, S. 6, 591-614.

Tsai, Yafang (2011), "Relationship Between Organizational Culture, Leadership Behavior and Job Satisfaction”, BMC Health Services Research, Vol. 11, No. 1, 98.

Uppal, Sharanjit (2005), "Disability, Workplace Characteristics and Job Satisfaction", International Journal of Manpower, Vol. 26, No. 4, 336-349.

Ülgen, Hayri; Mirze, S. Kadri (2013), Işletmelerde Stratejik Yönetim, 8. Baskı, İstanbul: Beta.

Vieira, Jose, A. Cabral. (2005), “Skill Mismatches and Job Satisfaction”, Economic Letters, Vol. 89, No. 1, 39-47.

Voelck, Julie (1995), "Job Satisfaction Among Support Staff in Michigan Academic Libraries", College and Research Libraries, Vol. 56, No. 2, 157-170.

Winstead, Barbara; Derlega, Valerian; Montgomery, Melinda; Pilkington, Constance (1995), "The Quality of Friendships at Work and Job Satisfaction" Journal of Social and Personal Relationships, Vol. 12, No. 2, 199-215.

Yelboğa, Atilla (2012), "Örgütsel Adalet ile İş Doyumu ilişkisi: Ampirik Bir Çalışma”, Ege Akademik Bakış, C. 12, S. 2, 171182.

Yener, Serdar (2018), “Psikolojik Rahatlık Algısının Otantik Liderliğin Sinizmin Üzerindeki Etkisinde Aracı Rolü”, Eskişehir Osmangazi Üniversitesi IiBF Dergisi, C. 13, S. 1, 1- 14. 


\section{Extended Summary}

\section{The Impact of Managerıal Effectiveness on Job Satisfaction at Small and Medium-Scale Hotels: The Example of Western Black Sea}

Technological developments have caused great changes in the life of society, and with the rapidly developing mechanization after the Industrial Revolution, the value of personnel management has increased even more in order to provide optimum benefit in production. In this context, in order to achieve the objectives of the organization, it is necessary to place emphasis on the job satisfaction of the employees. Because an employee who has achieved job satisfaction completes his commitment to the organization and, as a requirement of this, is motivated and endeavors with all his strength in line with the interests of the organization.

Tourism is one of the sectors that embody organizational structures in which job satisfaction is of great importance. Tourism is a labor-intensive industry. In this sector where people serve people, job satisfaction is gaining more importance with each day in order to ensure organizational commitment. Managerial effectiveness is very important in employee satisfaction. Therefore, in this study, the main purpose of the research is to measure the effect of managerial effectiveness on the job satisfaction of the employees. Another aim is to reveal whether there is a statistically significant difference in the job satisfaction of the employees according to their individual characteristics.

In line with these purposes, two hypotheses have been proposed. The first hypothesis put forth is: "managerial effectiveness affects job satisfaction positively;" and the second hypothesis is: "job satisfaction differs in terms of certain individual characteristics." Small and medium-sized hotels play an important role in the realization of tourism activities. Therefore, in this study, small and medium-sized hotels were determined as the field of application for the managerial effectiveness and job satisfaction variables that were addressed. While small and medium-sized hotels continue their activities, the job satisfaction of the employees must be sufficient for the achievement of the organizational goals. This is solely considered to be in parallel with the success of the managers in their managerial activities. Thanks to the balance between these two variables, businesses can continue to carry out their activities successfully.

In order to search for answers to the hypotheses put forward in line with the purposes of the study, the quantitative research approach was considered as the appropriate choice. The questionnaire technique was preferred as the data collection tool. The questionnaire used in the study consists of three parts. In the first part, there are questions about demographic features; in the second part, there are statements about administrative effectiveness; and in the third part, there are statements about job satisfaction. The questions and statements in the first two sections were created by the authors by making use of theses, articles and scientific literature for the purposes of the research. In the third part, a scale that had previously been validated and proven reliable in another study was used.

Small and medium-sized hotel employees in seven provinces of the Western Black Sea Region were preferred as the research universe. Since all employees cannot be reached due to time limitations and economic reasons, the sampling method was used and an easy sampling method was preferred. The most important reason for choosing this sampling method is that the number of employees differs parallel to the high and low seasons and the exact number cannot be determined. A total of 500 employees were wanted to be reached. However, 402 of the distributed questionnaire forms were returned. 388 of these forms were found to be useful on the grounds that there were incomplete and incorrect information on the rest of the questionnaires, and analyses were carried out on these 388 questionnaire forms.

The data obtained were subjected to reliability analysis, frequency analysis, t-test, ANOVA and regression analysis through the SPSS package program. As a result of the reliability analysis, the scales used were determined to be highly reliable. Parametric tests were decided to be used by examining the flatness and distortion values of the data. As a result of the analysis, it was revealed that most of the participants were male, single and in the 18-25 age group, and worked for minimum wage in terms of income. As a result of the percentage and frequency analysis; it has been concluded that business managers care about the thoughts of their employees, provide them with the opportunity to develop, pay their salaries and social security premiums regularly, and have regular permit practices. However, it has also been concluded that business managers fall behind in rewarding individual achievements and providing promotion opportunities. As a result of the t-tests, it was concluded there was no statistically significant difference in the job satisfaction of the employees according to gender, marital status, and educational status; whereas, there were statistically significant differences according to income level. As a result of ANOVA tests, it was concluded there was no statistically significant difference in the job satisfaction of the employees in regard to age; while there was a statistically significant difference according to their position in the enterprise.

As a result of the t-tests carried out in order to measure the differences that might occur according to the managerial effectiveness statements in job satisfaction; it was concluded that the managerial opportunities positively impact 
the job satisfaction of the employees. As a result of the regression analysis, it was concluded that the managerial efficiency explained job satisfaction in a meaningful way. This impact turned out to be $36 \%$. In other words, the $36 \%$ change in job satisfaction results from managerial effectiveness.

While the first hypothesis put forward was accepted as a result of the analyses performed in the study, the second hypothesis was partially accepted. The reason for the differences observed was presented as the income level of the employees and their position at the enterprise. Managers must administer wage arrangements in the best way to keep the job satisfaction of their employees at the highest level. The differences that occur due to the position held in the enterprise may be due to the physical difficulties of the work performed. Various suggestions have been made to hospitality executives and researchers who will conduct research on similar topics. 
Eskişehir Osmangazi Üniversitesi IißBF Dergisi 